\title{
Construcciones efímeras en madera: los balnearios de la fachada marítima de Alicante (siglos XIX y XX)
}

\author{
Ephemeral constructions in wood: the spas of the Alicante seafront \\ (19 ${ }^{\text {th }}$ and $20^{\text {th }}$ centuries)
}

$\underline{\text { Olga Grao-Gil }}^{(*)}$

\section{RESUMEN}

Durante los siglos XIX y XX, a lo largo de la geografía europea proliferaron los balnearios, edificaciones destinadas a facilitar los baños termales y marinos como fuente de salud, tan de moda en aquellos años. Como caso de estudio se analizan los de la playa de Alicante, primer puerto de mar comunicado con la capital española por ferrocarril y uno de los primeros focos de atracción del turismo del interior de la península. Los balnearios levantinos eran estructuras sencillas de madera, compuestas por plataformas cubiertas sobre el mar, apoyadas sobre pilotes enclavados en la arena, a modo de sofisticados muelles. De forma paradigmática, se analiza la construcción y tipología de uno de esos balnearios. Con este artículo se pretende demostrar la relevancia de estas edificaciones que, a pesar de su marcado carácter estacional, formaron parte del paisaje de la fachada marítima alicantina durante más de un siglo.

Palabras clave: balnearios; casas de baños; arquitectura balnearia; baños de mar; Alicante; construcción en madera; edificaciones estacionales; arquitecturas efímeras; turismo; talasoterapia; fachada marítima.

\section{ABSTRACT}

During the $19^{\text {th }}$ and $20^{\text {th }}$ centuries, throughout the European geography spas spread, buildings designed to facilitate sea and thermal baths as a source of health, so fashionable at that time. As a case study, those of the beach of Alicante, the first seaport connected to the Spanish capital by rail and one of the first attraction hubs of the tourism coming from the interior of the peninsula, are analyzed. The Levantine spas were simple wooden structures, composed of covered platforms on the sea, supported on foundation piles stuck in the sand as sophisticated piers. In a paradigmatic way, the construction and typology of one of these spas is analyzed. This article aims to demonstrate the relevance of these buildings that, despite their marked seasonal character, formed part of the landscape of Alicante seafront for more than a century.

Keywords: spas; bath houses; spa architecture; sea baths; Alicante; construction in wood; seasonal building; ephemeral architectures; tourism; thalassotherapy; seafront.

(*) Universidad de Alicante (España).

Persona de contacto/Corresponding author: olga.grao@ua.es (O. Grao-Gil)

ORCID: https://orcid.org/oooo-0oo3-1994-9331 (O. Grao-Gil)

Cómo citar este artículo/Citation: Grao-Gil, Olga (2020). Construcciones efímeras en madera: los balnearios de la fachada marítima de Alicante (siglos XIX y XX). Informes de la Construcción, 72(560): e359. https://doi.org/10.3989/ic.72887.

Copyright: (C) 2020 CSIC. Este es un artículo de acceso abierto distribuido bajo los términos de la licencia de uso y distribución Creative Commons Reconocimiento 4.0 Internacional (CC BY 4.0). 


\section{INTRODUCCIÓN}

Durante el siglo XIX y primera mitad del XX, cobraron gran importancia las terapias basadas en las propiedades medicinales de las aguas termales y marinas destinadas a mejorar la salud. Como consecuencia de ello, proliferaron por toda la geografía europea los balnearios, construcciones cuya finalidad era facilitar a los usuarios la toma de los baños y, en general, la práctica de este tipo de terapias curativas. Los tratamientos, prescritos normalmente por un médico especialista, abarcaban desde la repetición de sencillos baños fríos un número de días concretos y con una duración determinada dependiendo de su finalidad, pasando por los baños de agua caliente entre $25^{\circ} \mathrm{C}$ y $36^{\circ} \mathrm{C}$, las terapias con algas o barros, hasta los más variados chorros o afusiones (1).

Los establecimientos al servicio de la balneoterapia atendían a diferentes denominaciones: balnearios, casas de baños, baños marinos, estaciones balnearias, etc., y, como su nombre indica, se situaban al borde del mar o junto a un manantial con facultades terapéuticas. Muchos de ellos permanecen hoy convertidos en resorts de lujo donde acudir para realizar los más diversos tratamientos encaminados a mejorar la salud de sus usuarios, aprovechando las propiedades de las aguas cercanas.

Esta investigación se centra en los establecimientos destinados a la talasoterapia, es decir, al «uso terapéutico de los baños o del aire del mar». En concreto, se analizan los balnearios que poblaron la playa del Postiguet de Alicante, desde la segunda mitad del siglo XIX hasta bien entrado el siglo XX. El hecho de ser el primer puerto de mar comunicado por ferrocarril con la capital española, con las consecuencias de todo tipo que ello acarreó, convierten a Alicante en paradigma de lo que podría considerarse los albores de la ciudad turística costera y, por tanto, en interesante elemento de estudio en cuanto a las construcciones efímeras en madera que en ella se desarrollaron.

Existen numerosas menciones a los balnearios alicantinos en buena parte de la bibliografía sobre la ciudad, en la que se citan como elemento configurador de la fachada marítima decimonónica. Historiadores, como V. Ramos Pérez, cronistas de la villa, como N. C. Jover, y estudiosos como F. Figueras Pacheco, F. Gil o el presbítero G. Vidal Tur, le dedicaron unas líneas. Destaca la monografía de C. Valdés y, más recientemente los escritos de A. Martínez Medina y los artículos de A. B. González Avilés et al. No obstante, esta investigación trata de reordenar toda esa documentación para, situados en el contexto histórico, entender la aparición de este tipo de establecimientos, la tipología edificatoria que adoptaron, así como la función socioeconómica que desempeñaron.

Tras una breve descripción del fenómeno del apogeo de los baños termales en Europa y de la aparición de un nuevo modelo urbanístico de ciudad, se estudiará el Chain Pier de Brighton, como propulsor de los baños de mar y de una nueva tipología edificatoria, la de los balnearios a modo de muelles sobre el mar. Se analiza el origen de los primeros balnearios de la playa de Alicante con el importante papel desempeñado por el ferrocarril, la tipología balnearia local, así como la solución constructiva en madera empleada. Tras el análisis de un ejemplo concreto de casa de baños como caso de estudio, se explica el declive y desaparición de este tipo de balnearios, para terminar extrayendo una serie de conclusiones finales de la investigación.

\section{EL FENÓMENO DE LA BALNEOTERAPIA}

Desde antiguas civilizaciones, la creencia en las propiedades terapéuticas del agua se ha mantenido arraigada, transmitiéndose a lo largo del tiempo. Si bien las primeras termas se remontan a la Grecia del siglo V a.C., los romanos fueron quienes convirtieron el termalismo en un hecho sociocultural, con complejos arquitectónicos de la categoría de las termas de Caracalla o Constantino. En España, romanos y árabes construyeron instalaciones alrededor de los manantiales naturales para aprovechar los beneficios de las aguas mineromedicinales y tratar así diversas enfermedades.

La aparición de la imprenta posibilitó la divulgación de textos sobre la materia, como el De Balneis et Thermis de Savonarola de 1485, considerado el primer tratado sobre balneoterapia (2). Le seguirían otros muchos, también en España, como la versión castellana de Historia Natural de Cayo Plinio Segundo, editada en 1629 o Espejo cristalino de las aguas minerales de España de A. Limón de 1697, consolidando la creencia en los poderes curativos de las aguas mineromedicinales (3). En 1877 se fundó la Sociedad Española de Hidrología Médica, consecuencia de la especialización en el tema, dado que desde hacía unas décadas era obligatorio que al frente de cada balneario hubiera un profesional médico convenientemente formado.

\subsection{Un nuevo modelo de ciudad: la ciudad balneario}

A finales del siglo XVIII, entre las clases sociales altas se extendió la moda de la toma de los baños como fuente de salud. La ciudad inglesa de Bath, a $150 \mathrm{~km}$ al sudoeste de Londres, comenzó a recibir la visita de monarcas y nobles en busca de las propiedades curativas de sus conocidas aguas termales -ya existían termas en época romana-, consolidándose como una de las primeras ciudad-balneario y posible origen de lo que es conocido hoy como turismo de salud. La falta de ejercicio, sumado a los malos hábitos alimenticios arraigados fuertemente en la sociedad, derivaba en enfermedades como la gota, reuma, problemas digestivos, cardiovasculares, etc., y las aguas termales solían aliviar los síntomas. Lo que podría haber sido una moda pasajera, se consolidó y se fue implantando en otros enclaves del norte de Europa, dando lugar a la aparición de nuevas ciudades balnearias, como las inglesas Brighton o Scarborough y la mencionada Bath, la francesa Vichy, la alemana Baden-Baden, la belga Spa - posible origen del nombre de este tipo de establecimientos-, o la bohemia Karlovy Vary.

Estas nuevas costumbres higiénicas y sociales tuvieron enorme impacto en las poblaciones que participaron del nuevo fenómeno. A nivel urbanístico, cambió la morfología de muchas urbes, y desarrolló otras nuevas, dotándolas de características propias bajo el modelo denominado ciudadbalneario. Largos bulevares cuajados de vegetación -en el caso de ciudades litorales, paseos marítimos junto al mar-, estaciones balnearias, hoteles, instalaciones deportivas, restaurantes, cafeterías con terraza y casinos que amenizaban las horas de asueto del incipiente turismo, eran algunos de los elementos comunes en este modelo urbano.

En el caso de estudio de Alicante, el modelo de ciudad balneario quedaría reflejado principalmente en su fachada marítima. Siguiendo las corrientes higienistas de la época, el 
Malecón, espacio público junto al puerto ganado al mar tras el derribo de las murallas de la costa, fue urbanizado en 1868. Se creó así un nuevo bulevar longitudinal paralelo a la costa, La Explanada, (Figura 1) con cuatro hileras de palmeras que delimitaban tres corredores para el paseo, al estilo de «une promenade des Anglais» - Niza, Francia- como diría P. Deffontaines en su estudio sobre Geografía Humana del Mediterráneo de la primera mitad del siglo XX (4). Dado su éxito de afluencia de público, en las décadas siguientes se prologó el paseo hacia el suroeste, conformando el parque de Canalejas, y hacia el noreste, junto a la playa del Postiguet, con el denominado paseo de Gómiz urbanizado en 1890. En total, unos dos kilómetros de frente litoral urbano en forma de paseos marítimos, a modo de corredor longitudinal continuo paralelo a la costa.

En torno a estos nuevos paseos, sobre todo en el central -la Explanada-, se levantaron en el último tercio del siglo XIX y primera mitad del XX, edificios residenciales de familias burguesas, que eligieron vivir frente al mar en construcciones que a menudo mostraban su alto poder adquisitivo en sus ornamentadas fachadas. Convertidos en foco de atracción de ciudadanos y visitantes, junto a los paseos se levantaron establecimientos de hostelería y equipamientos como hoteles, restaurantes, cafeterías, el edificio del Casino, el Real Club de Regatas, etc., al tiempo que se ofrecían todo tipo de entretenimientos, como ferias, conciertos, cine y teatro de verano, para amenizar las horas libres. A la vez, el contiguo paseo de Gómiz servía de marco a los numerosos balnearios que poblaban la playa del Postiguet en aquellos años.

En la actualidad, aunque con diversas modificaciones, los paseos litorales, ideados bajo la corriente higienista decimonónica como un continuo en el interfaz tierra-mar, siguen vertebrando la fachada marítima, consolidados como uno de los elementos más representativos de la ciudad de hoy.

\subsection{El Chain Pier de Brighton}

De la explotación de las aguas termales se pasó a la de las aguas marinas, mucho menos exclusivas y limitadas, con la construcción de muelles y plataformas sobre la costa que fa- cilitaban el acceso al mar de los bañistas, a la vez que se les dotaba de un nuevo espacio de recreo y relaciones sociales.

También se podría considerar de origen inglés el interés médico por los baños de agua salada y las estancias junto al mar. En 1822 se concluyeron los trabajos de transformación de una modesta villa al borde del mar en el fastuoso y moderno palacio de verano del príncipe Jorge IV: el Royal Pavilion. Se trataba de un retiro junto a la costa a la que el regente se desplazaba para tratar sus problemas de gota con baños de mar por recomendación médica. Esta circunstancia transformó Brighton, al inicio, de pequeño pueblo pesquero a lugar de atracción de aristócratas y gente adinerada que quería seguir las costumbres de la corte (5).

De 1823 es el Chain Pier - "muelle de la cadena" - de Brighton (Reino Unido), plataforma de casi $4 \mathrm{~m}$ de ancho construida en madera que, partiendo del acantilado, se adentraba $320 \mathrm{~m}$ en el mar. Tenía estructura novedosa, al estilo de un puente, con el tablero horizontal suspendido de 8 cadenas de ahí su nombre- de hierro forjado a modo de cables, de las que nacían 362 varillas verticales en forma de tirantes de sujeción. La plataforma y las cadenas se apoyaban en cuatro altas torres de hierro fundido asentadas en el lecho marino. La cimentación era profunda, de unos $3 \mathrm{~m}$, compuesta por pilotes de madera de abeto (Figura 2. izquierda).

Fue concebida como muelle embarcadero, dado que Brighton carecía de puerto natural, pero en poco tiempo se convirtió en atracción turística. A pesar de que no fue la primera construcción de este tipo en erigirse, el Chain Pier, descrito en las guías de entonces como «un curioso espécimen de ingenio moderno y arte científico», acaparó todas las miradas. Hasta allí se desplazaban los visitantes que querían tomar los baños, pasear sobre el mar, asistir a los conciertos y espectáculos que se preparaban, contemplar los ocasionales fuegos artificiales que se ofrecían o hacer compras en los comercios instalados en las bases de las torres. Con la llegada del ferrocarril a Brighton en 1841, las clases populares empezaron a desplazarse también hasta allí para pasar su tiempo libre, con lo que la afluencia de público se disparó, llegando a acoger unas 4000 personas diariamente (7).

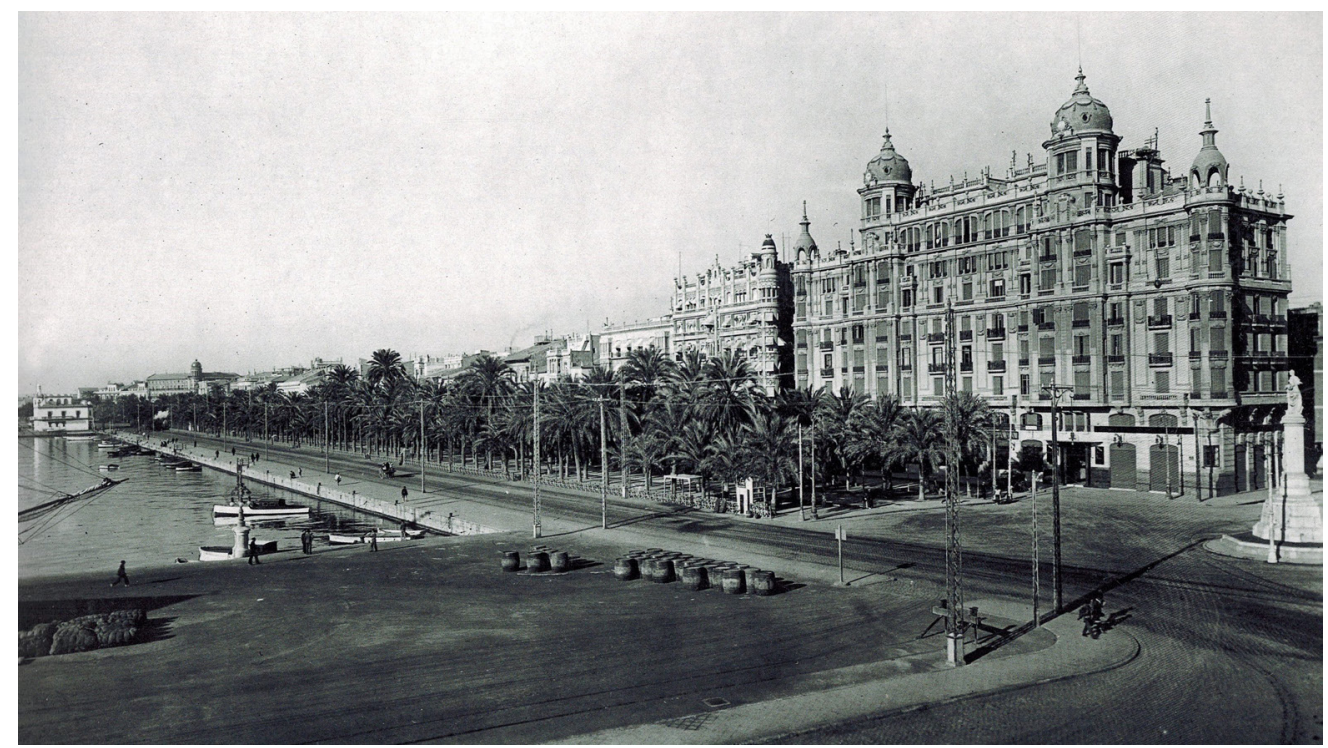

Figura 1. Paseo de la Explanada desde el puerto, con la Casa Carbonell en primer término. Alicante. 1926. [Fuente: Campos, $2007(6)]$. 

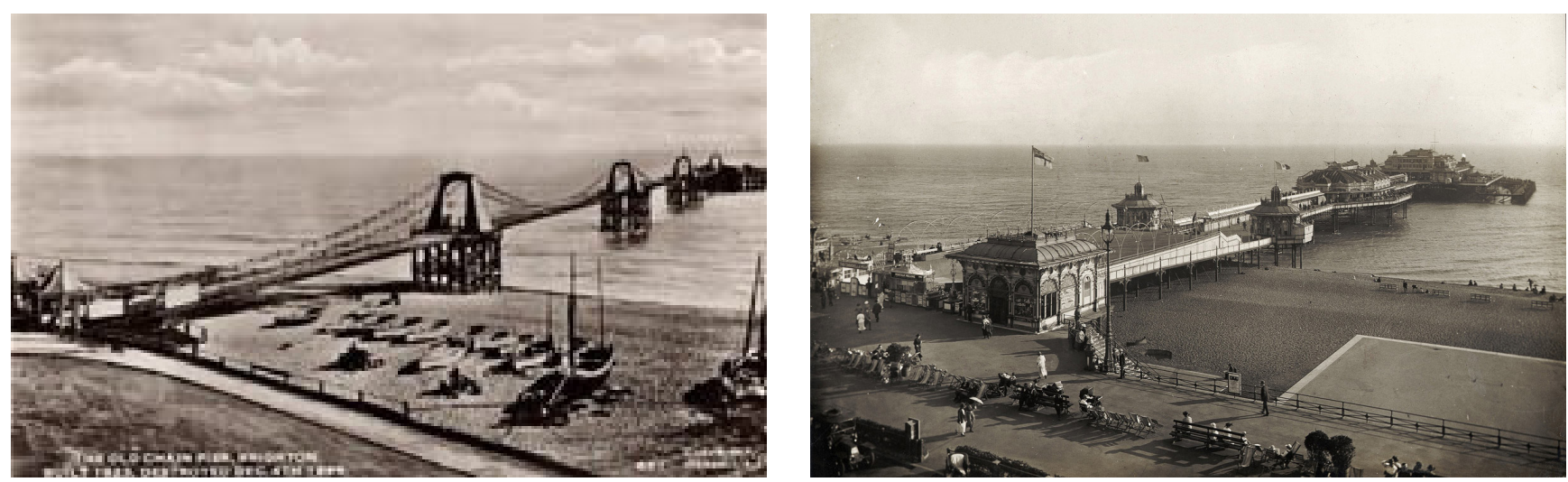

Figura 2. Izquierda: Chain Pier de Brighton. Derecha: West Pier de Brighton. [Fuente: Royal Pavilium and Museums Brighton and Hove].

Pasadas las primeras décadas entró en declive, sobre todo a partir de la construcción en 1866 de West Pier, también en Brighton, que acabó siendo el nuevo foco de atracción de los turistas por sus novedosas instalaciones (Figura 2. derecha). Se trataba de un muelle similar al Chain Pier pero más moderno y sofisticado, ya que incorporaba un quiosco de música, un pabellón y una sala de conciertos. Estuvo en pie, aunque cerrado y deteriorado a partir de 1975, hasta que varios incendios acabaron con él en 2003.

El Chain Pier, después de numerosas reconstrucciones, tras sufrir los estragos de fuertes vientos, golpes de mar, etc., fue destruido definitivamente por una gran tormenta en 1896. Se podría considerar como uno de los propulsores de lo que sería el turismo de baños de mar, donde se trataba de disfrutar de los beneficios de toda índole que el entorno marino proporcionaba. Nacían así las casas-balneario sobre el mar, novedosa tipología edificatoria, derivada en gran medida de los tradicionales muelles, que surgía para dar respuesta a la demanda de nuevos espacios para los baños de salud y de ocio.

\section{LOS BALNEARIOS DE LA PLAYA DEL POSTIGUET}

En España, promovido por la realeza, la burguesía y las élites políticas, los baños de mar se convirtieron a mediados del siglo XIX en un hábito identificado con una clase social con alto poder adquisitivo. La reina Isabel II era asidua de las playas de San Sebastián y el rey Alfonso XIII de los baños de Santander. La burguesía adoptó la costumbre aristocrática de trasladar su residencia al litoral durante el período estival para beneficiarse de las brisas y las aguas marinas. Nació así el concepto de segunda residencia y los nuevos destinos de veraneo, como Tarragona, Bayona, Murcia, Cádiz, Castellón y, cómo no, Alicante.

A Alicante, esta moda de los baños de mar la trajeron los comerciantes europeos afincados en la ciudad, sobre todo franceses, en las primeras décadas del siglo XIX. Ya en el Boletín de la Provincia de 1834 se anunciaba una invitación refrescante para bañarse y en ese mismo año se instalaron en el puerto unos módulos flotantes compartimentados y dos casetas fijas en la orilla, para que las familias pudieran disfrutar del baño con una cierta comodidad. Debido a las obras de remodelación del puerto, enseguida se trasladó la oferta de baños a la contigua playa del Postiguet, donde permanecería durante décadas (Figura 3).

Los baños debían tomarse bajo prescripción médica, como afirmaba el doctor alicantino P. Pérez, en 1908, en su libro Utilidad de los baños de mar, «formulados de idéntica manera que la receta se envía a la farmacia». Asimismo, en él establecía reglas y precauciones a considerar a la hora de tomar los baños, así como la duración óptima de los mismos (8). En definitiva, se trataba de un tratamiento médico más, basado en las propiedades del agua y de las brisas marinas. El clima favorable de la ciudad y la buena temperatura del agua, incluso más allá de los meses propios del verano, convirtieron a Alicante en un destino perfecto para explotar las virtudes de la talasoterapia.
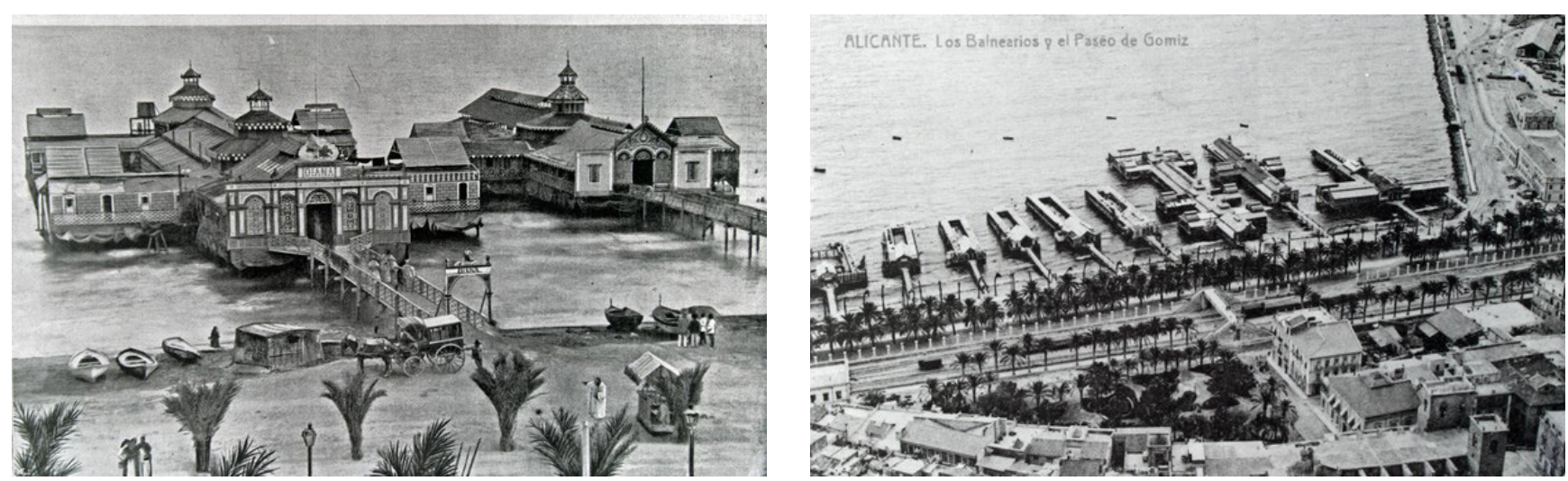

Figura 3. Izquierda: Imagen de dos de los balnearios. 190o. Derecha: Imagen de la playa del Postiguet de Alicante, con el paseo de Gómiz ya urbanizado, en la que se aprecia la existencia de numerosos establecimientos balnearios funcionando al mismo tiempo. 1917.

[Fuente: Archivo Municipal de Alicante, colección F. Sánchez]. 


\subsection{La llegada del ferrocarril}

La extensión del fenómeno de la balneoterapia a las masas populares llegaría de la mano del ferrocarril. La línea ferroviaria que unía Madrid con Alicante, primera ciudad litoral comunicada por tren con la capital, quedó terminada el 4 de enero de 1858. Unos meses después, el 25 de mayo de ese mismo año, la reina Isabel II de Borbón, con su estancia en la ciudad durante unos días, inauguraba oficialmente la línea (9) y, con ello, una nueva etapa de tránsito de personas y mercancías con el interior de la península y, en definitiva, el inicio de lo que podría denominarse actividad turística, una de las principales fuentes de riqueza de la ciudad.

La mayor parte de compañías ferroviarias, desde que apareciera el ferrocarril en Europa en 1830, ofertaban viajes directos hacia las estaciones balnearias. Se ofrecían billetes desde la capital a 60 reales (15 pesetas) en segunda clase y a 33 reales $(8,25$ pesetas) en tercera (10). Era el comienzo de la popularización del turismo de balnearios, reservado hasta entonces a las clases con mayor poder adquisitivo, que se extendió a otros sectores de la población con menor capacidad económica. Así lo reflejaba el diario el Eco del Comercio de Alicante, según lo publicado el 25 de julio de 1868:

«Una inmensidad de gente forastera recorre hace dos días las calles de Alicante, y los trenes llegan sin cesar atestados de viajeros que vienen no solo de Madrid, sino de muchos pueblos de Castilla y de la Mancha a respirar las auras marinas [...]» (11).

En 1893, en la línea Alicante-Madrid, se inauguró un tren turístico de bajo coste que permitía a los viajeros estancias en la época estival en Alicante para tomar los baños. Era conocido popularmente con el nombre de tren botijo, posiblemente por el recipiente que portaban los viajeros para calmar la sed en las 14 horas que duraba el trayecto entre la capital y Alicante. La Compañía MZA, propietaria de la línea ferroviaria, anunciaba en sus folletos «Temporada de baños de mar en la costa del Mediterráneo. Gran rebaja de precios», junto a diferentes fechas, itinerarios y tarifas. En 1894, el billete de ida y vuelta de Madrid a Alicante costaba 20 pesetas, en segunda clase, y 12 pesetas, en tercera, precios muy competitivos en la época. A menudo, se ofertaban paquetes completos que incluían el billete de tren de ida y vuelta, estancia en hotel o pensión y pases para el balneario.

Este tren de bajo coste, con una media de 30 ooo viajeros por año, estuvo funcionando hasta 1917 (12). Dado su enorme éxito, al destino inicial de Alicante se fueron uniendo pronto otros, como Murcia, Granada, Cádiz, San Sebastián, La Coruña, Santander, Gijón y Bilbao.

\subsection{Hacia la consolidación de una nueva tipología edificatoria}

Las nuevas necesidades producen nuevas arquitecturas. La búsqueda de las propiedades terapéuticas del agua marina hizo que se adaptara un tipo edificatorio existente, el del muelle-embarcadero, largos siglos empleado como nexo de unión entre la tierra y el mar, para reconvertirlo en un nuevo uso que facilitara el acceso a los baños, generando toda una infraestructura en torno a esta actividad. Se necesitaban espacios para cambiarse de ropa con privacidad, para tomar los baños lejos de miradas indecorosas y con elementos de apoyo para todos los que no sabían nadar, muy común en aquellos días. Y no se trataba solo de una necesidad meramente funcional. Paralelamente, se generó una demanda social que reclamaba la creación de puntos de encuentro y de relaciones sociales, de esparcimiento y bienestar, con una importante componente económica a la vez, pues pronto se convirtió en fuente de riqueza de muchas localidades que albergaron este tipo de establecimientos.

De este modo, de la estructura sencilla del muelle surgió una edificación cubierta sobre las aguas, es decir, se generaron nuevos tipos que desarrollaron una tipología. El diccionario de la lengua española define el término tipología como «el estudio y la clasificación de tipos que se practica en diversas ciencias». En el ámbito arquitectónico que nos ocupa, entendida como la disciplina que estudia los diferentes tipos arquitectónicos, la tipología se encargaría de analizar esos tipos edificatorios surgidos para dar respuesta a las nuevas necesidades, es decir, los balnearios, y clasificarlos según su morfología, distribución, estacionalidad, tipo de construcción, materiales empleados, etc.

Como afirma J.F. Vera (13), «En cuanto a tipología de las construcciones, las formas arquitectónicas de los establecimientos de baños de mar conjugan las funciones terapéuticas y de ocio, con unas connotaciones diferentes a las formas tradicionales [...]. Las mismas fachadas dan una imagen en la que se plasma la motivación de esparcimiento en unas estructuras falsamente fastuosas». $\mathrm{Al}$ mismo tiempo, recuerda que esta arquitectura debe valorarse en el entorno en el que se desarrolló, es decir, en playas cercanas al casco urbano, recorridas por paseos tradicionales de palmeras, lugar preferente con vistas al mar escogido para su ubicación por prestigiosos hoteles y restaurantes, donde se ofrecía todo tipo de actividades lúdicas.

Nuestro caso de estudio se centra en los balnearios aparecidos a mediados del siglo XIX en el litoral urbano de la ciudad de Alicante. Sus características son muy diferentes de los tipos edificatorios de los balnearios que coetáneamente se estaban construyendo junto a las aguas medicinales de manantiales, como el catalán de Vichy (1898); de aquellos levantados en torno a las propiedades curativas de las aguas y los lodos, como el gallego de la Toja (1907); o los de las costas cantábricas del País Vasco, como el de Algorta o Igeretxe (1868), o las atlánticas de Cádiz, como el Gran Balneario Victoria (1907), que requerían construcciones que se adaptaran a las grandes diferencias en el nivel del mar provocado por las mareas del océano (Figura 4).

Todos ellos, herederos de los balnearios decimonónicos surgidos por toda Europa, no solo realizaban funciones terapéuticas, en forma de casa de baños, sino también residenciales, adoptando tipología de hotel -incluso a veces de sanatorio marino, como el de Gorliz (Vizcaya) - y de establecimiento de ocio. Para tal fin, requerían de arquitecturas de obra permanentes, a menudo monumentales - en consonancia con sus ilustres huéspedes-, con fachadas de corte clásico o historicista, muy alejadas de las construcciones efímeras en madera del Levante español.

\subsection{Características de los establecimientos balnearios}

Alicante, por ser la primera ciudad marítima comunicada con la capital por ferrocarril, fue uno de los primeros destinos 

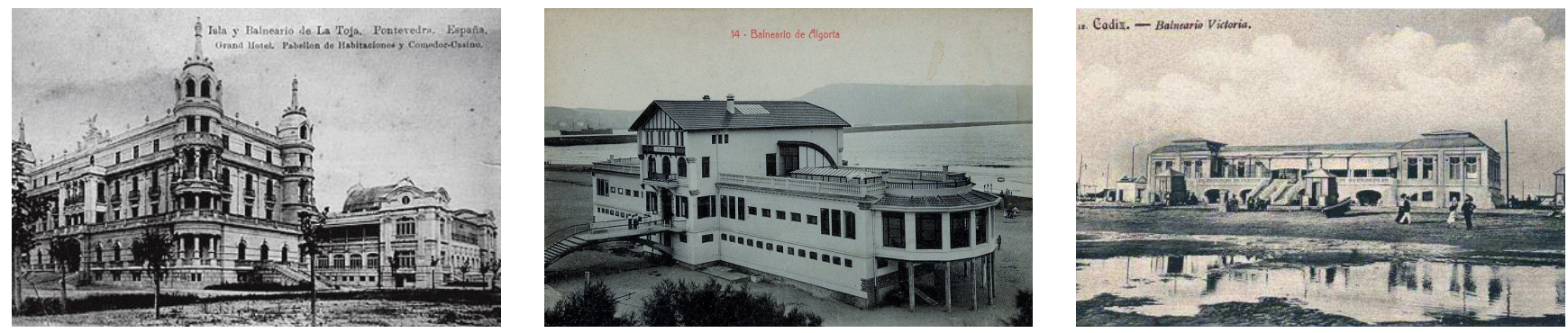

Figura 4. Izquierda: Fotografía del Balneario de La Toja (Pontevedra) donde se aprecia el Grand Hotel, pabellón de habitaciones y ComedorCasino. [Fuente: https://www.elmundo.es/suplementos/magazine/2007/411/1186758705.html]. Centro: Fotografía del Balneario de

Igeretxe (Vizcaya) de 1920 aproximadamente. [Fuente: https://www.hotel-igeretxe.com obtenida del Archivo Fotográfico de las Bibliotecas del Aula de Cultura de Getxo]. Derecha: Fotografía del Gran Balneario Victoria (Cádiz). [Fuente: Archivo Histórico Provincial de Cádiz].

litorales en acoger visitantes del interior que llegaban para tomar los baños de mar. Esta circunstancia hizo que fuera pionera en la construcción de establecimientos balnearios con unas características propias diferenciadoras.

Todas las casas de baños de la playa de Alicante tenían en común el tratarse de construcciones sencillas, de una sola planta a modo de plataforma cubierta y elevada sobre el mar, apoyadas sobre pilotes anclados en el lecho marino, a las que se accedía a través de una pasarela, que partía de la playa o del paseo marítimo (Figura 5). Más que construcciones, se podría afirmar que la mayor parte de ellas eran meras instalaciones provisionales que se montaban en época estival y se retiraban cuando finalizaban los meses de baño. Se levantaban sobre el mar, en la playa urbana de Alicante - playa del Postiguet- basadas en concesiones administrativas.

Dado que los establecimientos balnearios se situaban en lugares de dominio público, debían dar servicio a los diferentes grupos sociales, ofreciendo incluso baños a las clases más desfavorecidas por un precio económico. Se delimitaba de esta manera el espacio litoral, mediante zonas y horarios, para evitar que se mezclaran bañistas de diferente condición social. Igual distinción se hacía entre sexos, acotando el espacio de baño separado entre hombres y mujeres, dejando normalmente a los niños en el lado de las mujeres. De 1847 es un curioso bando, que se conserva en el Archivo Municipal de Alicante, en el que se delimita con concreción la zona de baños de hombres y mujeres, a la vez que «se prohíbe a toda clase de personas el bañarse tanto de día como de noche sin ir decentemente cubiertos. La contravención a cualquiera de estas disposiciones será castigada con la multa de 10 a 30 reales de vellón [...]» (15).

Las primeras ordenanzas reguladoras de los baños de mar datan de 1818, lo que permite hacerse una idea de lo pionera que fue Alicante en esta actividad (16). Desde mediados del siglo XIX contó con varios establecimientos, si bien de alguno de ellos - el denominado de Simó- se tienen noticias de su existencia con anterioridad. Entre 1860 y 1960 se documentan más de una docena de balnearios, bajo las siguientes denominaciones: La Alianza, La Confianza (antes Neptuno), Diana, Ferrocarril, La Rosa, La Esperanza (antes Simó), Nuevo Neptuno, El Madrileño, La Florida, Las Delicias, La Estrella, Playa del Postiguet, El Águila, El Almirante, Ferrandis y Guillermo. Y entre 1920 y 1930: El León y La Alhambra (antes la Esperanza) (17). Tres de ellos, La Alianza, Diana y La Esperanza, tenían carácter permanente, es decir, no se desmontaban al concluir el periodo estival. Hubo un tiempo en que coexistieron entre 8 y 10 establecimientos a la vez, lo que permite deducir la importancia que su actividad llegó a tener.

J. Aller y Vicente, en su Guía de Alicante para el año 1900 (18), habla de la existencia de 11 balnearios al mismo tiempo y se refiere a los tres establecimientos permanentes afirmando que «están abiertos todo el año y son generalmente los más concurridos por la aristocracia. [...] Todos ellos reúnen muy buenas condiciones», y además de los baños de mar «hay pilas de zinc y de mármol dentro de las habitaciones, en las que pueden bañarse con agua a mayor ó menor temperatura [...] para lo cual las citadas pilas tienen grifo de agua fría y caliente, así como barómetros para graduar la temperatura
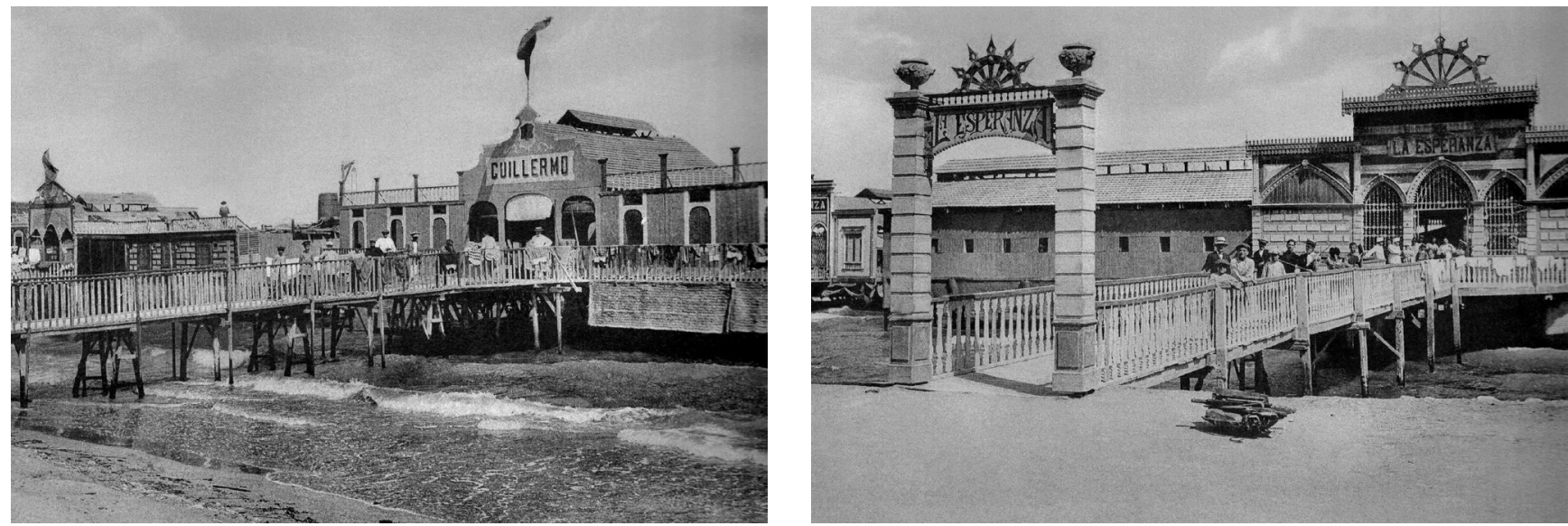

Figura 5. Izquierda: Fotografía del acceso al Balneario Guillermo. Alicante. 1912. Derecha: Imagen del pontón y fachada del Balneario La Esperanza. Alicante. 1912. [Fuente: Guilabert 2008, 259, 261 (13)]. 
y aparatos para duchas. Los establecimientos son extensos y no carecen de elegancia; el servicio es esmeradísimo, cuentan con guardarropía y servicio de carruajes». Con respecto a la función social que desempeñaban las casas de baños, más allá de la puramente terapéutica, describe lo siguiente: «tienen galería que corre por el lado exterior con puertas o ventanas para la ventilación y luz, bancos en los andenes y terrazas, donde se instalan tertulias o se dedican al descanso los bañistas».

Las casas de baños solían estar distribuidas en planta rectangular. En los más sofisticados, una vez se subía por el pontón o pasarela, se accedía al hall y a las estancias comunes, así como a un salón central iluminado por las fachadas y los tragaluces. Superado este primer cuerpo principal, el establecimiento desplegaba pequeñas cabinas en serie, conformando largas galerías exteriores que encerraban un hueco central rectangular a modo de patio, que no era más que el propio mar que acogía a los bañistas (Figura 6 izquierda). Cada compartimento individual solía tener una sencilla escalera con salida directa al mar. Las alas enfrentadas de baños compartimentados albergaban usuarios diferenciados por sexo. También existían balnearios, coincidentes normalmente con los permanentes, de mayor envergadura, con planta en forma de cruz.

Los establecimientos ofrecían al bañista duchas, casetas para el cambio de ropa, dependencias con bañera para la toma de baños calientes, restaurante, cabinas individuales con salida directa al mar, espacios a la sombra e incluso tienda de artículos para la venta. $Y$ es que no era únicamente un centro para terapias de salud, se trataba de ofrecer al cliente un agradable espacio para el ocio, que invitara a las relaciones sociales e hiciera más placentera la estancia en la playa.

\section{SOLUCIÓN CONSTRUCTIVA EN MADERA}

Como es sabido, las edificaciones balnearias de la playa alicantina se componían de estructuras de una planta que se adentraban en el mar, sobre una plataforma enclavada en el lecho marino. Dado su marcado carácter estacional, requerían de un material de construcción económico y que fuera fácil de transportar y montar y que, a ser posible, fuera reutilizable para poder darle uso durante varias temporadas. La madera fue el material idóneo empleado en aquellos años para este tipo de construcciones desmontables. Así lo atestiguan otras arquitecturas efímeras coetáneas de la fachada marítima como son: los tinglados provisionales del puerto, levantados en la segunda mitad del siglo XIX en los muelles para acopio de mercancías y maquinaria y que, ya entrado el siglo XX, fueron sustituidos por edificaciones de fábrica y estructura metálica; el teatro de verano, que se montaba en época estival al inicio del parque de Canalejas, compuesto por una sencilla construcción de madera, con cubierta a dos aguas y amplio aforo al aire libre, donde se representaba todo tipo de actuaciones teatrales y musicales para amenizar la estancia de los bañistas; o la primera sede del Real Club de Regatas de Alicante, construcción flotante de paneles de madera situada junto al muelle de costa, levantada por un maestro carpintero en 1889 y que fue sustituida dos décadas después por un edificio de obra de estilo historicista.

\subsection{Cimentación y estructura}

Dado que las edificaciones consistían en plataformas elevadas cierta altura sobre el nivel del mar, para su apoyo uniforme se recurría a un tipo de cimentación profunda de tipo puntual usada desde la antigüedad: el pilotaje. Consistía en un entramado de rollizos de madera - los pilotes-, de diámetro más o menos uniforme, hincados en el lecho marino mediante el golpeo suave y repetido en la parte más gruesa del tronco.

Para preservar sus características el mayor tiempo posible y protegerlos del ataque de hongos e insectos, normalmente los pilotes se impregnan de una sustancia protectora previamente a su colocación. La práctica ausencia de mareas en el Mediterráneo hacía que estos pilotes estuvieran permanentemente sumergidos, circunstancia que les beneficiaba de cara a una mayor durabilidad, frente a las instalaciones balnearias del cantábrico o del atlántico donde las importantes diferencias en el nivel del mar derivaban en alternancias continuas de periodos de sequedad y humedad, nocivos para la durabilidad de la vida útil del rollizo de madera.

Los pilotes, al igual que los pilares, componían una retícula uniforme, separados cada 3 o $4 \mathrm{~m}$ de distancia, conformando el entramado sobre el que asentar la tarima de la casa de baño. En numerosas ocasiones, el pilote presentaba en su parte visible una ménsula en la que descansaban escuadras
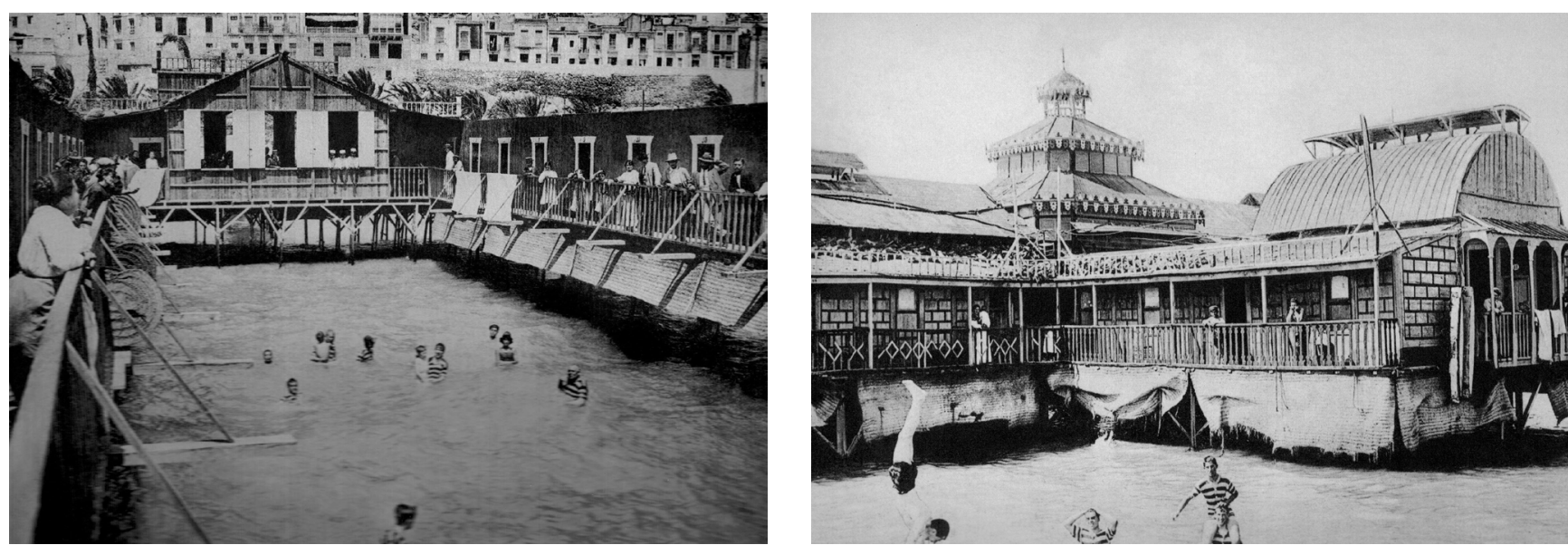

Figura 6. Izquierda: Imagen del interior de los baños Madrid. Alicante. 1912. Derecha: Fotografía del Balneario Diana, uno de los más sofisticados. Alicante. 1912. [Fuente: Guilabert 2008, 259, 262]. 
de refuerzo para el apoyo del forjado, o incluso arriostramiento con tirantes de rollizos de madera, a modo de cruces de san Andrés. A medida que se introdujo el hierro en la construcción, los pilotes de madera se sustituyeron por otros metálicos con cimentación de base hidráulica, sobre todo en los balnearios permanentes (19).

\subsection{Forjado y sistema de cerramientos}

Sobre los pilotes hincados se levantaba una plataforma a nivel, también en madera, a modo de forjado continuo, en el que se desarrollaba toda la actividad sobre el mar en una única planta.

El acceso a dicha plataforma se realizaba a través de una pasarela del mismo material, de no más de $2 \mathrm{~m}$ de anchura y protegida por barandillas, que partiendo de la misma playa - o del paseo de Gómiz a partir de 1892, año en que fue urbanizado - iba ganando en altura, hasta alcanzar el nivel de la tarima del balneario sobre el mar, desembocando en su acceso principal. Para dotar de monumentalidad al conjunto, se erigía un portón - a veces de obra- previo a la pasarela que enmarcaba el acceso.

La fachada principal de la casa de baños era uno de los elementos más visibles de la misma y a la que con más esmero se trataba por su carácter representativo. A menudo incluía elementos que aludían a sus propias denominaciones, como el balneario Diana, con referencias a la diosa clásica, o el balneario La Estrella, con decoraciones de estrellas en su fachada. Buena parte de ellas incorporaban decoración pintada de estilo clasicista, con recercado de vanos y balaustradas como remate superior simulando una azotea, como el denominado Guillermo o La Rosa. Otros optaban, en cambio, por la corriente historicista tan de moda en la época, con arcadas de estilo árabe como el balneario La Alhambra, como medio de dotar de fingida suntuosidad al conjunto.

Si bien los establecimientos permanentes llegaban a incorporar elementos de fábrica y cerrajería en sus fachadas, en la mayoría de los casos se trataba de sencillos paneles de madera decorados, a menudo con geometría y dimensiones diferentes del resto del conjunto, que se adosaban, con mayor o menor pericia, a la estructura general de la edificación. El sistema de cerramientos verticales, al igual que el resto de fachadas, lo componía un conjunto de paneles de madera desmontables.

\subsection{Cubierta}

La cubrición empleada comúnmente era la cubierta plana, para las galerías laterales destinadas a los baños, y la cubierta a dos aguas, para las salas principales y el hall de acceso del balneario. Se trataba de soluciones de cubierta sencillas, dado el tipo de estructura en madera de que se trataba. No obstante, hay documentada una cubierta parcial en bóveda de cañón -en el balneario denominado Diana (Figura 6 derecha)- y mencionar que las cubiertas a dos aguas de los balnearios de mayor envergadura presentaban en numerosas ocasiones la cumbrera sobre elevada, con aberturas longitudinales, a modo de tragaluces corridos, facilitando la ventilación natural de las estancias y galerías sobre el mar.

Las casas de baño de mayores dimensiones - que solían coincidir con las permanentes-, distribuidas en planta en forma de cruz, enfatizaban el crucero con cubriciones que emulaban los cimborrios catedralicios, estructurados en varios niveles y coronados por cúpulas, que a menudo recordaban a la arquitectura árabe o a las pagodas orientales, de marcada tendencia historicista al gusto de la época.

\section{EL BALNEARIO LA ALIANZA}

A modo paradigmático, se realiza el estudio de un caso concreto de balneario, el denominado La Alianza, que fue uno de los pocos establecimientos que, aunque con muchas modificaciones, permanecieron en la playa alicantina hasta su definitiva desaparición en los años 60. Se toma esta casa de baños como muestra de análisis, por un lado, por la existencia de documentación, en forma de fotografías (Figura 7) y planos del balneario, que facilita el análisis e interpretación de este tipo edificatorio y, por otro lado, por la sencillez de su distribución y estructura, lo que da una idea de base del organigrama funcional de esta clase de establecimientos, extrapolable al resto de muestras de esta tipología analizada. No obstante, hay que considerar que existen diferencias entre lo proyectado y lo construido, a la vista de las fotografías. Además, - los planos son de 1877- a lo largo de las décadas que estuvo en pie fue ganado en complejidad.

Con planta en forma de cruz (Figura 8) - que recuerda a la arquitectura religiosa-, disponía de tres elementos diferenciados, con la misma dimensión de crujía en planta: un cuerpo longitudinal principal en perpendicular a la orilla y dos cuerpos transversales a éste, ambos de mayor altura libre y menor longitud. Uno de los cuerpos transversales se situaba en el acceso al balneario, haciendo las veces de recibidor e incorporando a su vez, adosado, el panel de la fachada superpuesta. El otro cuerpo transversal creaba un crucero, con espacios interiores diferenciados del resto y cubrición representativa. Se desarrollaba en una única planta, a la que se accedía a través de una pasarela de madera de escasa entidad, protegida con barandillas del mismo material.

Asentada sobre una cimentación a base de 54 pilotes de metal, de $0,2 \mathrm{~m}$ de diámetro, hincados en el lecho marino, soportando una plataforma de madera de unos $900 \mathrm{~m}^{2}$ (20), la estructura consistía en una retícula de pilares bidireccional de 6 × 6 m. Cada uno de los módulos tenía doble crujía, quedando la hilera intermedia de pilares marcando el eje central de cada uno de los corredores. En todo el perímetro se disponía de un corredor exterior de $1 \mathrm{~m}$ de anchura en voladizo, a modo de balcón corrido, protegido por barandillas de madera.

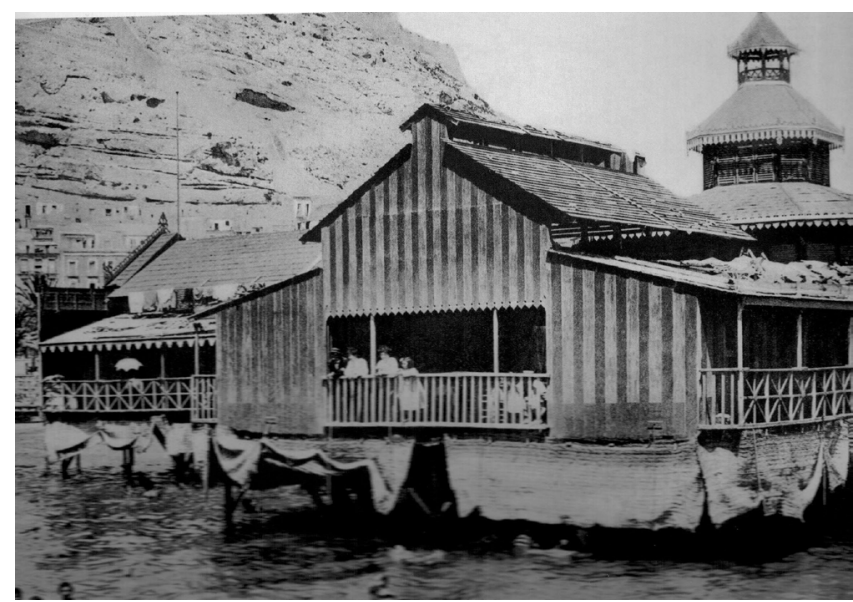

Figura 7. Imagen de una de las alas del Balneario La Alianza. 1912. [Fuente: Guilabert 2008, 260]. 


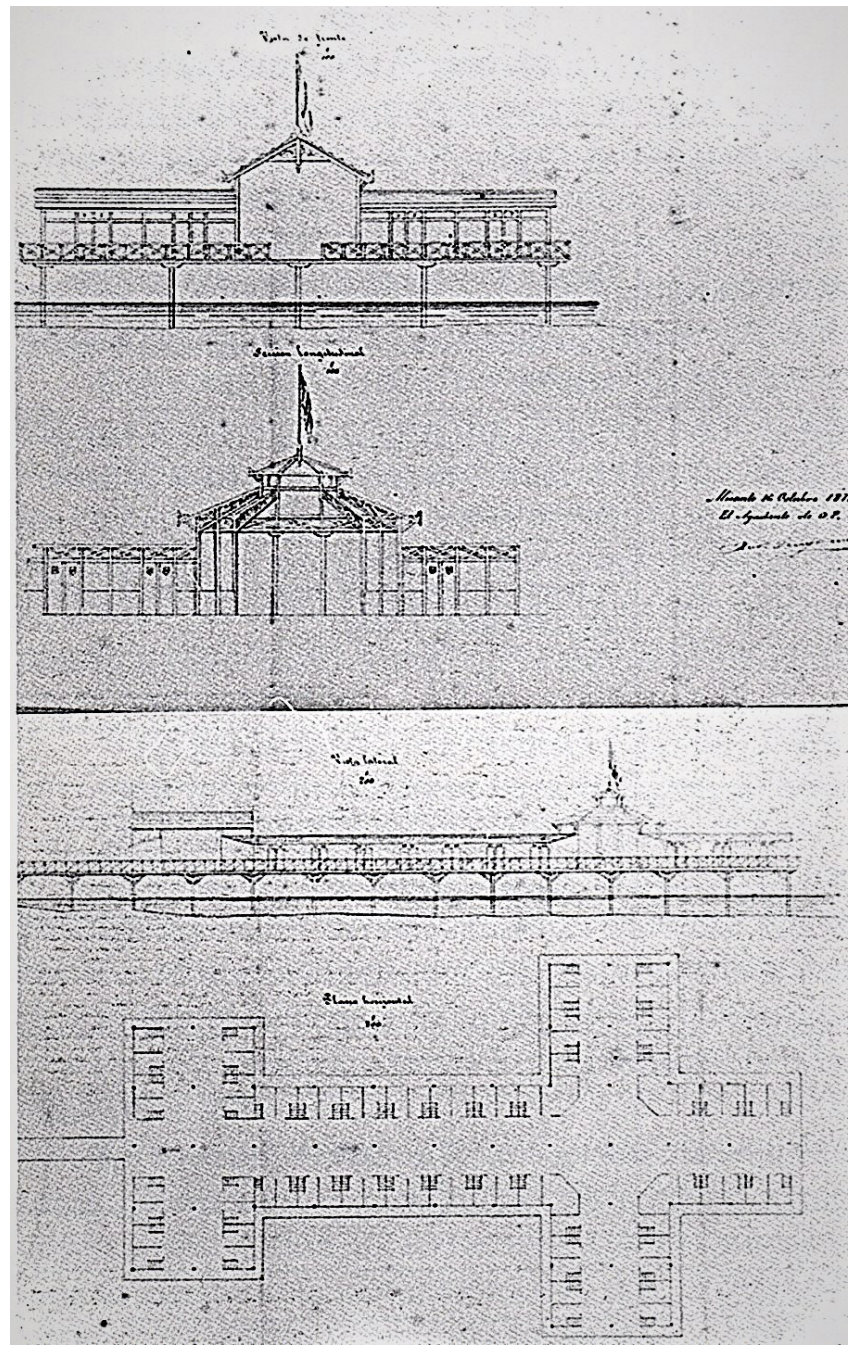

Figura 8. Planos de planta, alzado y secciones del Balneario La Alianza. 1877. [Fuente: Vera 1987, 56].

La distribución interior se repetía en los tres módulos, con una secuencia de cabinas compartimentadas de iguales dimensiones a ambos lados de un amplio corredor central. Cada una de dichas cabinas contaba con ventana al exterior, lo que les proporcionaba ventilación y luz natural, y con acceso directo al mar mediante una escalera que permitía a los usuarios tomar los baños justo debajo con cierta privacidad - entre la plataforma y el exterior se colocaban lonas para impedir la visión-.

La cubrición de los módulos se realizaba mediante cubierta a dos aguas - apoyada en vigas inclinadas rigidizadas con correa y tirante (21) - , sobre elevando el corredor central, de mayor altura libre que las cabinas. Se dejaban aberturas longitudinales, entre ambos niveles y en la cumbrera, para favorecer la ventilación natural interior. A menudo, se cubrían con chapas metálicas. El crucero, espacio noble, se enfatizaba mediante cubierta en forma poligonal, al estilo de las pagodas orientales, desarrollada en varios niveles, decreciente en tamaño a mayor altura, rematada por una suerte de linterna.

\section{EL DECLIVE DE LOS BALNEARIOS}

A partir de los años 30 del pasado siglo, se produjo un cambio en los hábitos sociales, aparecieron nuevas técnicas medicinales y los tratamientos de talasoterapia quedaron algo obsoletos y pasados de moda. No obstante, aunque se redujo el número de balnearios, los que quedaron ganaron en dimensiones, calidad y servicios, en un intento por conservar la afluencia de turistas, que empezaban a decantarse por otras opciones de veraneo.

Mencionar, por un lado, que en Alicante en esos años se dio prioridad a la actividad portuaria y los balnearios de la playa del Postiguet constituían un obstáculo para el normal desarrollo de las obras del puerto. En este contexto, la Junta de Obras del Puerto, en 1927, solicitó que no se otorgaran más concesiones temporales a los balnearios, proponiendo al mismo tiempo que se abriera un concurso para la construcción de un único balneario de obra, con carácter permanente, para sustituir a los existentes. Por otro lado, durante los bombardeos de la Guerra Civil varios balnearios quedaron fuertemente dañados y no se volvieron a levantar.

Además de estas consideraciones, un papel importante en la decadencia de los baños de mar lo tuvo la irrupción del automóvil que comenzó a popularizarse, una vez superada la Guerra Civil y los duros años de Posguerra. Este hecho favoreció que muchas personas tuvieran acceso a playas fuera de concesión administrativa. Los propios usuarios empezaron a tener la capacidad de elegir su lugar de vacaciones, más allá del destino concreto adonde el tren podía llevarlos. Del turismo de balnearios se pasó, a partir de los años 60 y 70, al turismo de sol y playa, con nuevas necesidades y nuevas arquitecturas, convirtiendo Alicante y su comarca costera en segunda residencia de población local y de habitantes del interior.

Los dos últimos establecimientos que permanecían en pie en la playa del Postiguet una vez pasada la moda de los balnearios, denominados La Alianza y La Alhambra (Figura 9), fueron derribados el 25 de mayo de 1969, dando por concluida así una etapa de generalización de los baños de mar que duraría más de un siglo, cambiando para siempre el curso de la historia de la ciudad de Alicante.

\section{CONCLUSIONES}

A partir del siglo XIX, se empiezan a poner de moda las terapias de salud basadas en las aguas de las fuentes termales y, posteriormente, en las propiedades del mar. Lo que al principio estuvo reservado a la nobleza y a la burguesía, poseedores de un mayor poder adquisitivo, pronto se extendió a las cla-

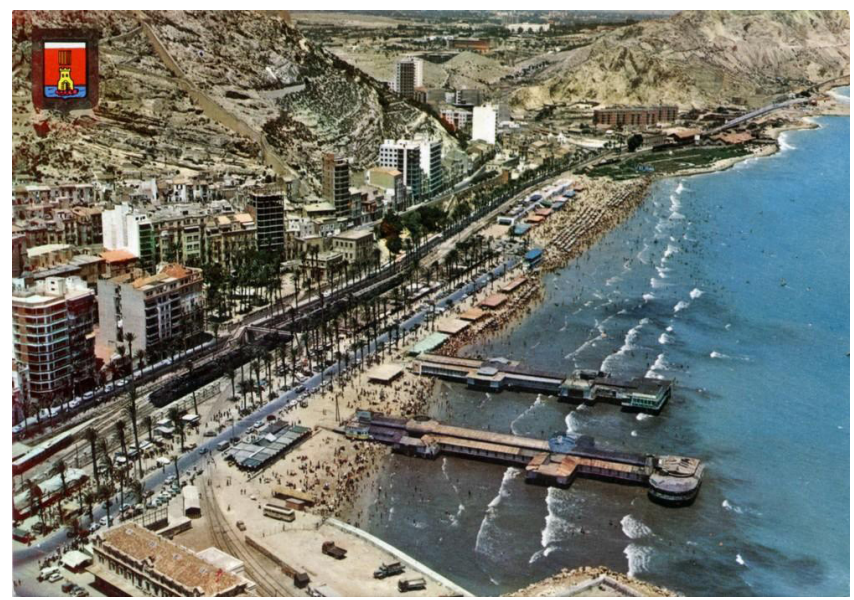

Figura 9. Fotografía aérea de la playa del Postiguet donde se aprecian dos balnearios, los últimos en desaparecer. 1968. [Fuente: Archivo Municipal de Alicante]. 
ses populares bajo la firme creencia en las bondades que estos tratamientos reportaban a la salud, considerados en aquellos años verdaderos tratamientos medicinales.

El fenómeno de la popularización de la balneoterapia no hubiese sido posible sin la aparición de la máquina de vapor que revolucionó el transporte marítimo y ferroviario, posibilitando el acceso a las fuentes termales y a la costa de los habitantes del interior. Alicante es buena muestra de ello, dado que fue la primera ciudad costera comunicada por ferrocarril con la capital española, lo que supuso el inicio de la actividad turística en la zona.

Las casas de baños, que proliferaron en la segunda mitad del siglo XIX y principios del XX en Alicante, consistían en sencillas construcciones en madera de una planta, que se adentraban en el mar a modo de plataformas cubiertas sobre pilotes enclavados en el lecho marino. Se podría considerar que el nuevo tipo arquitectónico aparecido deriva de la tradición de la construcción de muelles, como referencia primigenia de edificación de transición entre la tierra y el mar. Solían tener distribuciones similares, bien con planta longitudinal y largos corredores en torno a un hueco central, al que volcaban las estancias independientes para el baño, o bien con planta en forma de cruz, algo menos habitual. Ofrecían al bañista todo tipo de servicios, no solo para la puesta en prác- tica de la talasoterapia, sino también para amenizar las horas de asueto.

En torno a estos establecimientos se desarrollaron toda una serie de actividades complementarias que modificaron la fachada marítima de la ciudad. Se abrieron nuevos hoteles y restaurantes para dar servicio a los visitantes, a la vez que en los recién urbanizados paseos litorales se realizaban todo tipo de acciones culturales y de entretenimiento, como conciertos, ferias o teatros al aire libre, destinadas a amenizar el tiempo de ocio una vez acabada la hora del baño.

Salvo contadas excepciones, se trataba de arquitectura efímera, dado que tenían un marcado carácter estacional: se montaban para la temporada de baños y se retiraban cuando la época estival llegaba a su fin. De ahí el empleo de la madera como material de construcción principal por tratarse de un elemento económico, manejable, fácil de montar y de trasladar, y reutilizable.

Los establecimientos balnearios, a pesar de atravesar un periodo de una cierta decadencia a partir de los años 30, permanecieron en pie hasta el último tercio del siglo XX. Para entonces, el imparable avance del turismo de sol y playa había comenzado a dictar las normas que consolidarían Alicante como la ciudad turística que conocemos hoy.

\section{REFERENCIAS}

(1) Gil de Arriba, Carmen (1994). La práctica social de los baños de mar. Establecimientos balnearios y actividades de ocio en Cantabria (1868-1936). Documents d'Anàlisi Geogràfica, 25, 79-99. Recuperado de https://www.raco.cat/index. php/DocumentsAnalisi/article/view/41651/52459

(2) Melgosa Arcos, F.J. (2000). Turismo de salud: Termalismo y Balnearios. Blanquer Criado, D. (coord.), III Congreso de turismo, universidad y empresa (pp. 359-386). Benicasim: Tirant lo Blanch.

(3) Cava Mesa, M. J. Balnearios y baños de ola en Bizkaia. Itsas Memoria. Revista de Estudios Marítimos del País Vasco, 6 , 369-380. Recuperado de http://um.gipuzkoakultura.net/itsasmemoria6/369-380_cavamesa.pdf

(4) Ramos Hidalgo, A. (1984). Evolución urbana de Alicante, p.208. Alicante: Instituto de Estudios Juan Gil-Albert y Diputación de Alicante.

(5) Martínez Medina, A. (2012). Del hospital al balneario: arquitecturas para tratar y prevenir las enfermedades. En M. Pascual Artiaga et al (Eds.), Trobades (pp. 57-101).

(6) Campos Ferrara, S. (2007). Historia Gráfica del Puerto de Alicante, p.168. Madrid: Autoridad Portuaria de Alicante.

(7) Royal Pavilium and Museums Brighton and Hove (5 de febrero de 2019). Chain Pier. Recuperado de https://brightonmuseums.org.uk/discover/2012/07/05/chain-pier/

(8) Vera Rebollo, J. F. (1987). Turismo y urbanización en el litoral alicantino, p.53. Alicante: Instituto de Estudios Juan Gil-Albert.

(9) López Peral, Ma A., Louis Cereceda, M. y García González, E. (2017). La incorporación del hierro a la construcción en Alicante: la llegada del ferrocarril a la ciudad. Informes de la Construcción, 69 (548): e229, doi: https://doi.org/10.3989/ ic. 16.110

(10) Gil Sánchez, F. (1979). Crónicas de la Terreta, p.143. Alicante: Caja de Ahorros Provincial y Excma. Diputación de Alicante.

(11) Llorca Baus, C. (coord.) (1990). 100 Años del Real Club de Regatas de Alicante, p. XXI. Alicante: Real Club de Regatas de Alicante.

(12) 150 años de ferrocarril de Alicante (2 de abril de 2019). Viajeros hacia el mar: los balnearios. Recuperado de http://15oferrocarrilalicante.catedradr.com/historia/historia.asp?ID=2\&tema $=7$

(13) Vera Rebollo, J. F. (1987). Turismo y urbanización en el litoral alicantino, p. 62. Alicante: Instituto de Estudios Juan Gil-Albert.

(14) Guilabert Requena, J. (2008). Alicante en Blanco y Negro. Recuerdos de una ciudad y del mar, pp. 259-262. Alcoy: Ed. Tívoli.

(15) Archivo Municipal de Alicante (28 de abril de 2019). Galería de imágenes exposición playa Postiguet y Balnearios en los fondos del Archivo Municipal. Recuperado de https://www.alicante.es/es/galeria-imagenes/galeria-imagenesexposicion-playa-postiguet-y-balnearios-fondos-del-archivo

(16) Ramos Hidalgo, A. (1984). Evolución urbana de Alicante, p.228. Alicante: Instituto de Estudios Juan Gil-Albert y Diputación de Alicante. 
(17) Vera Rebollo, J. F. (1987). Turismo y urbanización en el litoral alicantino, p. 55. Alicante: Instituto de Estudios Juan Gil-Albert.

(18) Aller y Vicente, J. (1900). Guía de Alicante para el año 19oo. Alicante: Such y Serra.

(19) Vera Rebollo, J. F. (1987). Turismo y urbanización en el litoral alicantino, p. 63. Alicante: Instituto de Estudios Juan Gil-Albert.

(20) González Avilés, A. B., Pérez Millán, M.I. y Rubio Bellido, C. (2016). Sea baths as an example of sustainable architecture without an ecological footprint. WIT Transactions on The Built Environment, 21O, 221-232. doi: https://doi. org/10.2495/SDP160191

(21) González Avilés, A. B., Pérez Millán, M.I. y López López, J.M. (2015). Bath construction at the Spanish Mediterranean seaside: maritime heritage for the coast environment. WIT Transactions on The Built Environment, 148, 125-134. doi: https://doi.org/10.2495/CC150111 